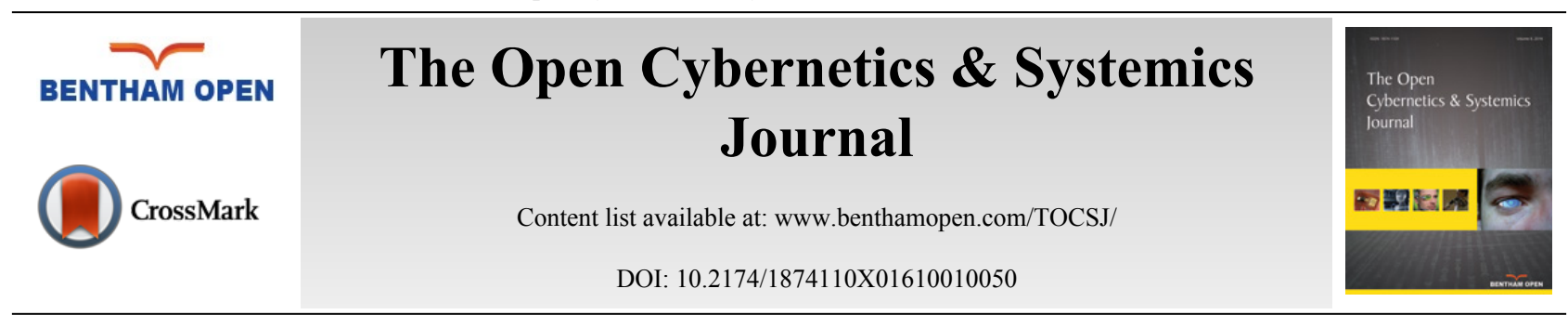

\title{
Study on the Distribution Optimization of Emergency Material Reserves
}

\author{
Xiangjing $\mathrm{Mu}^{1,2, *}$, Jikun Guo ${ }^{1}$, Xianwu Sun ${ }^{1}$ and Jun Dai ${ }^{1}$ \\ ${ }^{1}$ Department of Management, Logistical Engineering University, Chong Qing, 401311, China \\ ${ }^{2}$ College of Logistics, Naval Engineering University, Tian jin, 300450, China
}

\begin{abstract}
In this paper, the emergency material reserves have reasonable distribution in space, we discuss the general method for determining the location optimization of emergency material reserves. On the basis of security direction, security participating units, the initial guarantee tasks and related parameters, the paper proposed three kinds of optimization models: to build new reserve points, adjust the number of varieties and adjust the security task. The paper presents a new idea for the distribution optimization of emergency material reserves.
\end{abstract}

Keywords: Analysis model, Centroid method, distribution of reserve, emergency materials, reserve points, site selection.

\section{INTRODUCTION}

Emergency material reserve is the reserve activity of a nation made in advance for securing the supply of emergency materials. The fundamental aim is to bridge the gap on the number and time of emergency materials, so that the continuous supply of emergency materials can be ensured. The distribution optimization of emergency material reserves is to make the emergency material reserve has reasonable distribution in space, and meet the principle of proximity security. It can not only reduce transportation budget, but also accelerate security speed. The aim of distribution optimization of emergency material reserves is to select good places for reserves where the minimum of transportation cost and best security efficiency can be guaranteed. That is to say, reserves should be selected to places that firstly can meet the demand of security of emergencies and play the role of efficiency security; secondly, in the present situation, can reduce the security cost to the minimum $[1-3]$.

\section{THE DISTRIBUTION OPTIMIZATION PROCESS OF EMERGENCY MATIERIAL RESERVES}

\subsection{The Determination of Initial Security Task}

The prediction of overall consumption quantity. On the basis of effect factors such as security task, demand standard, security time, etc., scientific prediction is made on emergency material demanding quantity at some direction. Through the selection on different decision aims and the different calculation methods, the comprehensive decision results of emergency material demanding quantity is formed, and the predicted quantity of consumption is determined.

The determination of material demanding quantity in diverse security directions. Under the circumstance of emergency, the material security demand usually involves many directions, and the demanding quantities in different directions are not the same. The distance between every direction and security unit is also different [4]. To realize the security optimization from multi-point to multi-point, firstly, we should base on the predicted consumption quantity as well as the emergency material demanding quantity in each direction.

\footnotetext{
* Address correspondence to this author at the Department of Management, Logistical Engineering University, Chong Qing, 401311, China; Tel: +86 15922141490; E-mail: Tong_Jean@163.com
} 
The determination of security unit and its task volume distribution [5]. Based on emergency material security requests, relevant security unit is selected, and initial security task of each unit is determined, including the demanded quantity and kinds of materials. We used Dijkstra and its improving calculation to calculate road optimization, and got the security distance (road minimum) from each security unit to each security direction, so that to provide decision evidence of reserve distribution optimization.

\subsection{The Selection of Optimization Model for Reserve Distribution Optimization}

Based on the initial security task, we can choose one from the three models. The model of building new reserve points, the model of adjusting reserve variety \& quantity, and the model of adjusting security task, so that we can make the reserve distribution optimization [6].

\subsection{New Reserves Establishment}

Through the calculation of the shortest path of each security unit and various operational direction, if the shortest distance between all the security units and the operational directions is larger than the corresponding maximum security distance of the security unit, new reserves are required to be built; with the centroid method that is based on arbitrary coordinates, the closest centre point to all the node security distances in the network made up of nodes of each operational direction.

\subsection{The Adjustment of the Number of Reserve Varieties}

When the material reserve varieties and quantity of a selected security unit can not satisfy the demand of a task, adjustment of them should be made according to the results of security optimization calculation, by newly adding and dilatation approaches. The system selects the best adjusting object and the varieties and quantity that are required to adjust according to the calculation results of path optimization from multi-point to multi-point, as well as capacity size of each security unit [7].

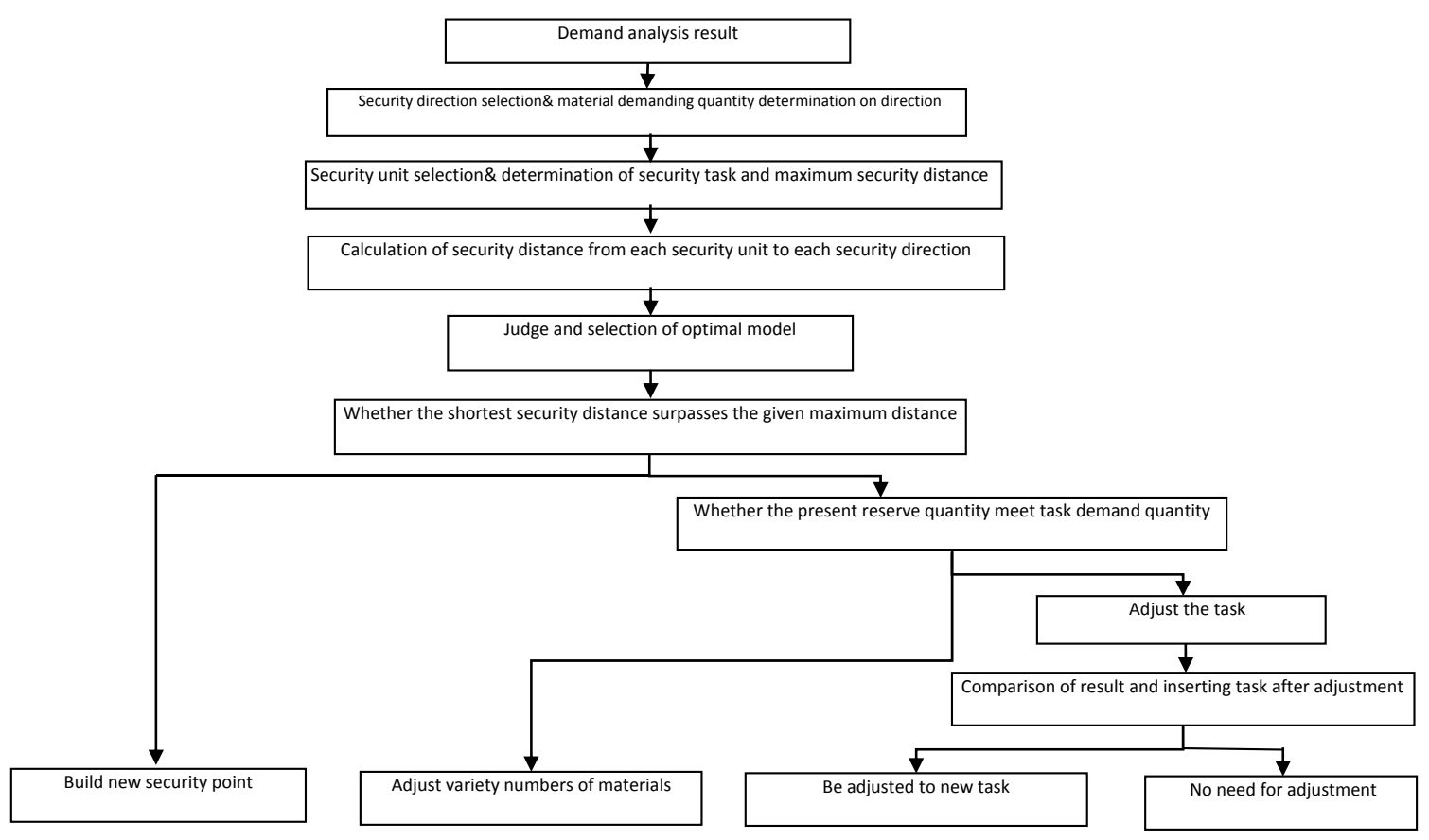

Fig. (1). Emergency material reserve distribution optimization procedure chart.

\subsection{The Adjustment of Security Scheme}

When the variety and quantity of material reserve of a selected security unit can satisfy the requirement of a task, through the analysis of path security optimization, in accordance with the principle of shortest time, shortest path and optimal efficiency, adjustment on the initial scheme is carried on to reallocation tasks of different security units. Also security scheme was made for departments' decision-making. The procedure chart is shown in Fig. (1). 


\section{THE REALIZATION OF OPTIMIZATION PROBLEM ON NEWLY-BUILT RESERVE POINT BASED ON CENTROID METHOD UNDER ARBITRARY SYSTEM OF AXES}

Centroid method is way of distributing single facility [8]. The solving principle of centroid method is "the sum of force moment is zero" in mechanics. That is to say, to get the force moment of every point quality to the coordinate axis, their sum is zero. This method is usually used for the selection of reserve points. We have taken many factors such as the existed distances between facilities, the material quantity to be transported into comprehensive consideration. Its using premise is that there is no limitation to the candidate position, and suppose the geographical position and the demanded material of each demanded point, to each demanded point there are straight access, and the unit transportation fee is known. Centroid method is to take the reserve system of axis waiting to be determined into the overall security cost and efficiency expression formula, use the cost and efficiency expression formula to get the force moment sum of reserve position coordinates $\mathrm{X}$ and $\mathrm{Y}$, the applying force moment sum is zero, and get the result of geographical position coordinates. It doesn't consider the added special transportation fee on the condition of not being fully loaded. Mention that reserve point is supply point, and its quality direction has contrast direction to gravity of demanding point.

The centroid method firstly has to mark the position in the coordinate system of each demanding point, the purpose of which is to determine the relative distance of each point [9]. Coordinate system can be established randomly, in the practical position selection, latitude and longitude are often used to establish coordinate. Then, according to the horizontal and vertical coordinates of each point in the coordinate system, based on the fact that the force moment is zero, the best location coordinates $\mathrm{X}$ and $\mathrm{Y}$ that have minimum transportation cost and security benefits are calculated.

\subsection{The Model Assumptions}

1. The demanded quantity w of each demanding point is the actual demand of the unit, and the total amount is known.

2. In the emergency material security, transportation fee can be assumed to be proportional to distance d.

3. The priority of demanding unit that needs to be secured can be represented by a weighted coefficient $\mathrm{k}$.

4. The reserve point $\left(x_{0}, y_{0}\right)$ got from centroid method, is not an absolute point but relative. It is a scope.

\subsection{The Model Establishment and Solution}

\subsubsection{The Assumption Analysis}

Assuming the coordinates $\left(x_{\mathrm{i}}, y_{\mathrm{i}}\right)$ of each demand point $i=1,2,3 \ldots$; The selected reserve address is $\left(x_{0}, y_{0}\right)$; assuming that all roads, the transportation fee from each demanding point unit to unit material $p_{i}(i=1,2,3 \ldots)$; $d_{i}$ is the distance from each demanding point to original point (it can be a non-straight line distance, it can be the road mileage) $d_{i}=\sqrt{\left(x_{i}{ }^{2}+y_{i}{ }^{2}\right)}$, here it is calculated as the distance. The sum of materials needed by each demanding point is $w_{i}(i=$ $1,2,3 \ldots)$; The demanded coefficient of demanding point is $k_{\mathrm{i}}(i=1,2,3 \ldots)$; The greater the $k$ is, the bigger the meaning of securing the demanding point is, the more need for giving priority to the direction of gravity is; the gravity direction of reserve point is in contrast to that of the demanding points.

\subsubsection{Model Establishment}

\section{Model 1: Only Considering Economic Efficiency}

The economic efficiency of each demanding point to coordinate origin is $G_{i}=w_{i} p_{i} d_{i}$. Take it as the quality of the point.

$$
G_{0}=\sum_{i=1}^{n} G_{i}=\sum_{i=1}^{n} w_{i} p_{i} d_{i}(i=1,2,3 \ldots n)
$$

$\mathrm{G}_{0}$ is the economic efficiency sum of all the demanding points, which is the quality of reserves.

To get moment power of quality of each particle from $x, y$, because the sum of moment power is zero, we get:

$$
G_{0} x_{0}+\sum_{i=1}^{n} G_{i} x_{i}=0(i=1,2,3 \ldots n)
$$




$$
G_{0} y_{i}+\sum_{i=1}^{n} G_{i} y_{i}=0(i=1,2,3 \ldots n)
$$

In the formula, $\mathrm{G}_{\mathrm{i}}$ is the quality of each demanding point, is the quality of each reserve point. So we can get:

$$
\begin{aligned}
& x_{0}=\sum_{i=1}^{n} G_{i} x_{i} / G_{0}(i=1,2,3 \ldots n) \\
& y_{0}=\sum_{i=1}^{n} G_{i} y_{i} / G_{0}(i=1,2,3 \ldots n)
\end{aligned}
$$

Model 2: Considering Security and Economic Efficiency

The comprehensive efficiency of each demanding point to origin $G_{i}=w_{i} p_{i} k_{i} d_{i}$ we take it as the quality of this qoint.

$$
G_{0}=\sum_{i=1}^{n} G_{i}=\sum_{i=1}^{n} w_{i} p_{i} k_{i} d_{i}(i=1,2,3 \ldots n)
$$

Table 1. The data of each demanding point.

\begin{tabular}{|c|c|c|c|c|}
\hline Demanding Point & $\begin{array}{c}\text { Sum of Demanded } \\
\text { Material }\end{array}$ & Transportation Fee of Unit Distance & Coordinate of Security & $\begin{array}{c}\text { The Urgency of the } \\
\text { Demanded Security }\end{array}$ \\
\hline A & 500 & 75 & $(120,80)$ & 5 \\
\hline B & 80 & 42 & $(340,-150)$ & 3 \\
\hline C & 300 & 130 & $(-550,-800)$ & 1 \\
\hline D & 1200 & 35 & $(-460,713)$ & 7 \\
\hline E & 600 & 80 & $(661,90)$ & 8 \\
\hline F & 1500 & 60 & $(125,-190)$ & 5 \\
\hline G & 900 & 55 & $(-760,845)$ & 6 \\
\hline H & 120 & 30 & $(-321,-546)$ & 2 \\
\hline
\end{tabular}

It is the comprehensive demanding point, also known as the quality of the reserve point. The quality of each particle is the result of moment power to each $x, y$ axis, because the sum of moment power is zero, we can get:

$$
\begin{aligned}
& G_{0} x_{0}+\sum_{i=1}^{n} G_{i} x_{i}=0(i=1,2,3 \ldots n) \\
& G_{0} y_{i}+\sum_{i=1}^{n} G_{i} y_{i}=0(i=1,2,3 \ldots n)
\end{aligned}
$$

In the formula, $\mathrm{G}_{\mathrm{i}}$ is the quality of each demanding point, $G_{0}$ is the quality of each reserve point, so we can get:

$$
\begin{aligned}
& x_{0}=\sum_{i=1}^{n} G_{i} x_{i} / G_{0}(i=1,2,3 \ldots n) \\
& y_{0}=\sum_{i=1}^{n} G_{i} y_{i} / G_{0}(i=1,2,3 \ldots n)
\end{aligned}
$$

\subsection{Application Example}

We set each demanding point as A, B, C, D, E, F, G, H. A coordinate system is set, the original point is $(0,0)$, shown in the chart. The coordinate of each demanding point is $\left(\mathrm{x}_{\mathrm{i}}, \mathrm{y}_{\mathrm{i}}\right) i=1,2,3$..; the coordinate of the selected reserve address is $\left(x_{0}, y_{0}\right)$, also the result we require; the transportation fee of each demanding point unit distance is $p_{\mathrm{i}}(i=1,2,3 \ldots)$; $\mathrm{d}_{\mathrm{i}}$ is the distance between each demanding point and original point(it can be non-straight line distance but road mileage). The sum of materials required by each demanding point (not considering the variety of material, but the variety has to meet every demand of security)is $\mathrm{w}_{\mathrm{i}}(\mathrm{i}=1,2, \ldots 3)$; the security demanding factor of demanding point is $\mathrm{K}_{\mathrm{i}}(\mathrm{i}=1,2,3 \ldots)$; shown in Table $\mathbf{1 .}$ 
Model 1: Only Considering Economic Efficiency, $\mathrm{G}_{0}=19118281$.

According to formula (4) and formula (5), we can get the vertical and horizontal coordinate of M:

$x_{0}=-55906472556 / 191182819=-292.5$

$y_{0}=40649787377 / 191182819=212.6$

It is obvious that M $(-292.5,212.6)$ is an obtained reserve point, shown as in Fig. (2).

Model 2: Considering Security and Economic Efficiency

According to formula (6) we can get:=1018721494.

According to formula (9) and formula (10) we can get the vertical and horizontal coordinate of $\mathrm{N}$ :

$x_{0}=2.06933 \mathrm{E}+11 / 1018721494=-203$

$y_{0}=-4.35519 \mathrm{E}+11 / 1018721494=428$

It is obvious that $\mathrm{N}(-203,428)$ is another reserve point we obtained, shown in the following chart.

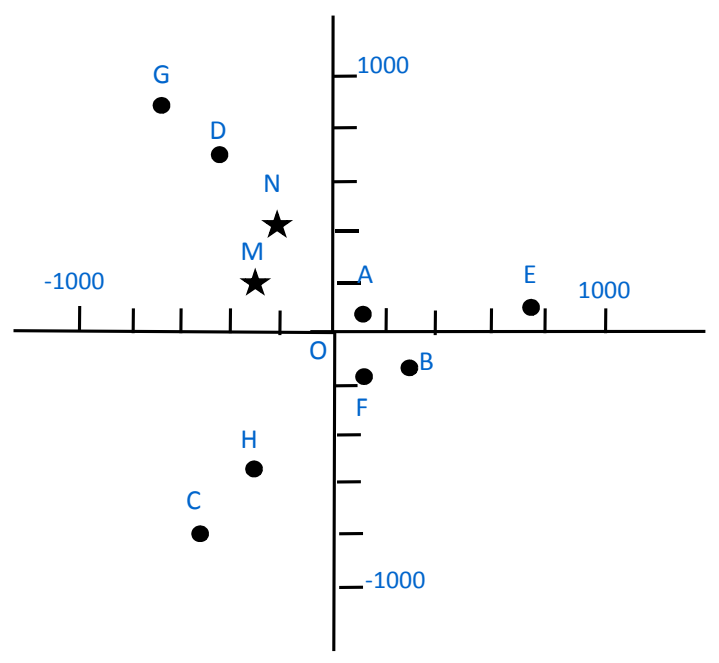

Fig. (2). The reserve point chart.

\section{CONCLUSION}

The paper has provided 3 kinds of optimization model. According to the determined security direction, the participated security unit, the initial security task, relevant parameters, etc., three kinds of optimization model "model of building new reserve point, model of adjusting variety number, and model of adjusting security task can be selected. Among these three, the model of adjusting variety number has dilatation and adjustment these two results; the model of adjusting security task has "required to be adjust" and "not required to be adjust" these two results.

\section{CONFLICT OF INTEREST}

The authors confirm that this article content has no conflict of interest.

\section{ACKNOWLEDGEMENTS}

This work is supported by the Education Science fund of the Military Science Institute of Beijing, China (No.2013JY368).

\section{REFERENCES}

[1] R. Zhang, Q. Zhou, and W. Xiong, "Updated a* algorithm and its application", Computer System and Application, vol. A9, pp. 98-107, 2009.

[2] W. Xiong, and R. Zhang, "A* algorithm and its application in GIS", Computer System and Application, vol. A4, pp. 14-17, 2007.

[3] J. Guo, and R. Zhang, "Updated diktra algorithm and its application in GIS", Computer System and Application, vol. A1, pp. 59-62, 2007.

[4] D.B. Clarke, A. Chatterjee, and S.M. Rutner, "Intermodal freight transportation and highway safety", Transportation Quorterly, vol. A2, pp. 
97-110, 1996.

[5] R.B. Copperman, M.P. Devlin, and R.M. Ewalt, "Coordinating and prioritizing multimodal transportation projects", In: Proceedings of Systems and Information Engineering Design Symposium. Charlottesvile, VA: USA, 2004, pp. 113-119.

[6] A. Lozano, and G. Storchi, "Shortest viable path algorithm in multimodal networks", Transportation Research, vol. A35, pp. 225-241, 2001.

[7] J. Guo, Logistics Optimization. Scientific Publishing Company: Beijing, 2010.

[8] R. Yu, and J. Wang, "Research on combination optimization of multimodal transportation system of containers", System Simulation Technology, vol. A4, pp. 272-275, 2009.

[9] C. Gang, B. Liu, and S. Kai, "Research on the selection of adaptive optimal transportation modes based on gray evaluation theory", Mathematics in Practice and Theory, vol. A3, pp. 57-63, 2007.

Received: August 9, 2015

Revised: September 27, 2015

Accepted: September 27, 2015

(C) Mu et al.; Licensee Bentham Open.

This is an open access article licensed under the terms of the Creative Commons Attribution-Non-Commercial 4.0 International Public License (CC BY-NC 4.0) (https://creativecommons.org/licenses/by-nc/4.0/legalcode), which permits unrestricted, non-commercial use, distribution and reproduction in any medium, provided the work is properly cited. 